\title{
A Surface-Silylated Single-Layer Resist Using Chemical Amplification for Deep-UV and Vacuum-UV Lithography
}

\author{
Kazuyuki SUGITA, Masahiro YAMASHITA, Kieko HARADA, \\ Masahito KUSHIDA and Kyoichi SAITO \\ Deptartment of Materials Technology, Chiba University, 1-33 Yayoi-cho, Inage-ku, \\ Chiba 263-8522, Japan
}

\begin{abstract}
KEYWORDS: TSI, pre-exposure silylation, bilevel strucure, high transmittance, alkaline development, plasma blanking.
\end{abstract}

\section{Introduction}

The increasing packaging density and shrinking critical dimension of electronic devices require resist systems with enhanced performance, including high resolution of an image delineated in a thin uniform layer, and high dry-etching durability enabled by a thick and flat layer covering the topography. Further, pattern transfer with the light of shorter wavelength is preferable for high resolution from the optical limitation, and high transmittance of the imaging layer is also required for the formation of a resist pattern of high aspect ratio.

The contradicting requirements for resist thickness can be released by surface imaging (SI). SI is a promising technology to expand the resolution limit of photolithography toward a half of or finer than the wavelength of the transfer-ring light. However, in the SI based on selective silylation in the exposed or in the unexposed area of the surface sublayer of the single thick layer, the selectivity is not always perfect, which causes unwanted partial silylation in the non-image area and a tapered depth profile of the silylated sublayer at the image/non-image boundary. As the results, the unwanted silylation must be removed by break-through etching prior to dry blanking of the thick bulk layer, and the linewidth of the silylated sublayer pattern depends on the duration of the break-through etching. Further, image expansion during silylation brings about resolution deterioration, i.e., line broadening or trench narrowing.

As a new type of SI, we proposed in recent papers [1-4] "Surface-silylated Single-layer Resist (SSS Resist)" prepared by uniform, pre-exposure silylation of a thick single layer of conventional resist polymer containing photoacid generator (PAG) to form a bilevel structure composed of a surface-silylated sublayer and an unsilylated bulk layer, instead of spin-coating with a Si-containing resist. Since the structure is quite similar to that of a bilayer scheme which uses a Si-containing resist, the SSS Resist was patterned similarly. The patterning scheme is illustrated in Fig. 1: imagewise exposure to generate acid from the PAG, postexposure bake (PEB) for chemically amplified desilylation, alkaline development of the sublayer, and dry blanking of the bulk layer by $\mathrm{O}_{2}$ RIE to form a positive pattern.

In the previous paper [4], we reported preparation of SSS Resists composed of the surface-silylated sublayer of around $200 \mathrm{~nm}$ thickness and the unsilylated bulk layer of 900-1,100 $\mathrm{nm}$, and clear pattern formation with a deep UV sensitivity of $7 \mathrm{~mJ} / \mathrm{cm}^{2}$.

However, patterning of this resist with vacuum and extreme UV radiation should be considered for the development of photolithography in near future. Since transmittance of a poly(vinyl phenol) (PVP) resist layer of $100 \mathrm{~nm}$ thickness is $19 \%$ at $157 \mathrm{~nm}$ [5] and $68 \%$ at $13 \mathrm{~nm}$ [6], the SSS Resist may be useful for VUV and EUV lithography, if the sublayer is thinner than $100 \mathrm{~nm}$.

In this paper, we studied silylation of the surface-sublayer as thin as possible, by optimizing the silylating conditions. 


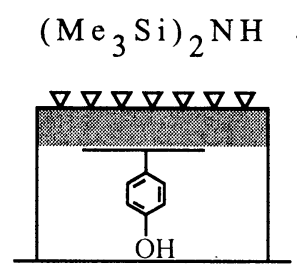

1. Silylation

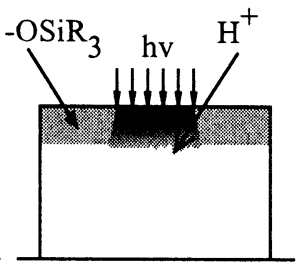

2. Exposure

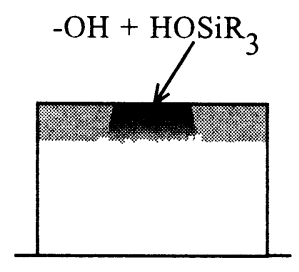

3. Desilylation during PEB

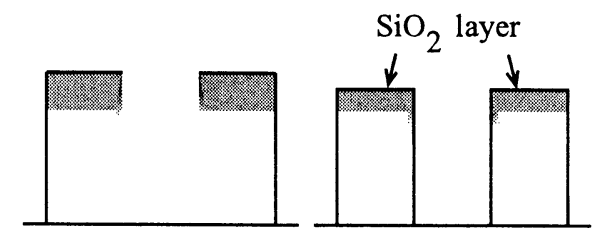

$\begin{array}{ll}\text { 4. Wet } & \text { 5. Dry blanking } \\ \text { development } & \text { by } \mathrm{O}_{2} \mathrm{RIE}\end{array}$

Fig. 1 Patterning process of SSS Resists.

\section{Experimental}

2.1 Specimen preparation

PVP $(\mathrm{Mw}=8,000)$ from Aldrich Co. was formulated with $8 \mathrm{wt} \%$ of triphenylsulfonium hexafluoroantimonate (TPS $\cdot \mathrm{SbF}_{6}$ ) in diethyleneglycol dimethyl ether (DGM). The resist layer was spin-coated from the PVP solution to an initial thickness of $1.0-1.2 \mu \mathrm{m}$ on a Si substrate, and soft-baked at $80{ }^{\circ} \mathrm{C}$ for $20 \mathrm{~min}$.

\subsection{Silylation}

Silylation was carried out in liquid phase by dipping the specimen in a solution containing $15-30 \mathrm{vol} \%$ of hexamethyl-disilaxane (HMDS), $1-2$ vol\% of DGM, and $69-83$ vol\% of $n$-decane at $75-95{ }^{\circ} \mathrm{C}$ for $20-50 \mathrm{sec}$ and rinsed twice in n-decane for $1 \mathrm{~min}$.

\section{$2.3 \mathrm{O}_{2} \mathrm{RIE}$}

The etch study was carried out in a parallel-plate etcher (electrode: $100 \mathrm{~mm} \phi$, distance: $40 \mathrm{~mm}$ ) equipped with a water-cooling system under operating conditions of $50 \mathrm{~W} / 13.56$ $\mathrm{MHz}$ net power and $\mathrm{O}_{2}$ pressure of $150 \mathrm{mT}$ Torr, at around $20^{\circ} \mathrm{C}$ for $3-10 \mathrm{~min}$. The etched depth was measured with a surface roughness analyzer, Kosaka Labs. SE3500.

The $\mathrm{O}_{2}$ RIE experiments were performed for two purposes: (1) the SSS Resist before imagewise exposure was etched with overlaying a metal mask partly over the specimen to estimate the durability and thickness of the surface-silylated sublayer, and (2) the SSS Resist after wet development was dry-blanked to the subsrate in the exposed area by using the surface-silylated sublayer in the unexposed area as an etch mask (Fig. 1, Step 5).

\subsection{Exposure, PEB and wet development}

The specimen was irradiated with a low-pressure $8 \mathrm{~W}$ mercury lamp, Toshiba GL-05, through a mesh mask, and baked in an air-circulating oven at $120{ }^{\circ} \mathrm{C}$ for $5 \mathrm{~min}$ with a beaker containing hot water at $75-80{ }^{\circ} \mathrm{C}$. Then, it was wet - developed in a $1.0-1.5 \mathrm{wt} \%$ aqueous tetramethyl-ammonium hydroxide (TMAH) solution at $23-26{ }^{\circ} \mathrm{C}$ for $1-10 \mathrm{sec}$ [In the case of large specimens for SEM pictures, TMAH concentration was a little higher and the duration was longer, i.e., 2-6 min.]

\section{Results and Discussion}

$3.1 \mathrm{O}_{2}$ RIE durability and sublayer thickness of SSS Resists

Preparation of $1-\mu \mathrm{m}$ thick SSS Resists with $100-\mathrm{nm}$ thin sublayers is the target of this study. However, $\mathrm{O}_{2}$ RIE durability, which is represented by the reciprocal ratio of the etching rate of the silylated sublayer to that of unsilylated layer etched simultaneously, should be high. The minimum requirement of silylation for preparing the surface sublayer to function as an effective etch mask is as follows:

(Sublayer thickness) $\mathrm{x}\left(\mathrm{O}_{2}\right.$ RIE durability) $\geqq$ (Initial thickness) - (Sublayer thickness) (i)

Then, the minimum value of the durability is calculated to be 9 , but a part of the silylated sublayer was found to dissolved into the developing solution. As a consequence of thickness reduction, the durability necesary for pattern formation was 20 or higher.

After SSS Resist \#34 which was reported in the previous paper [4], more than 15 times of silylation were studied in order to form a thin surface sublayer with high durability, revising the experimental conditions: concentrations of HMDS and DGM were increased and decreased, respectively; temperature of the silylating solution was raised, while the duration was once lowered and then raised with decreasing the DGM concentration.

Among them, patternable SSS Resists were prepared under the conditions cited in the upper half of Table 1. $\quad \mathrm{O}_{2}$ RIE durability was 28-43, and thickness of the silylated sublayer was 100-130 nm (SSS Resist \#34 is cited for comparison [4]). Typical etching rate dependence on the layer depth for Resist \#50 is shown in Fig. 2. 
Table 1 Silylation, patterning conditions, and resist performance

\begin{tabular}{|c|c|c|c|c|c|}
\hline SSS Resist No. & $\# 34$ & $\# 44$ & $\# 46$ & $\# 47$ & $\# 50$ \\
\hline $\begin{array}{lr}\text { HMDS conc. } & (\text { vol\%) } \\
\text { DGM conc. } & (\text { vol\%) } \\
\text { Silylating temp. } & \left({ }^{\circ} \mathrm{C}\right) \\
\text { Silylation time } & (\mathrm{sec})\end{array}$ & $\begin{array}{c}15 \\
5 \\
72 \sim 74 \\
60\end{array}$ & $\begin{array}{l}30 \\
1.5 \\
76 \sim 80 \\
20\end{array}$ & $\begin{array}{l}30 \\
1.5 \\
76 \sim 80 \\
20\end{array}$ & $\begin{array}{l}30 \\
1.0 \\
75 \sim 78 \\
20\end{array}$ & $\begin{array}{l}30 \\
1.0 \\
90 \sim 95 \\
50\end{array}$ \\
\hline $\begin{array}{l}\text { Sublayer thickness (nm) } \\
\mathrm{O}_{2} \text { RIE durability }\end{array}$ & $\begin{array}{l}220 \\
\times 38\end{array}$ & $\begin{array}{l}120 \\
\mathrm{x} 28\end{array}$ & $\begin{array}{l}100 \\
x 33\end{array}$ & $\begin{array}{l}130 \\
x 43\end{array}$ & $\begin{array}{l}100 \\
x 30\end{array}$ \\
\hline $\begin{array}{l}\text { PEB temp. } \\
\text { Hot water temp. } \\
\text { TMAH conc. } \\
\text { Develop. time } \\
\mathrm{O}_{2} \text { RIE }\end{array}$ & $\begin{array}{r}120 \\
80 \\
1.5 \\
2 \\
7\end{array}$ & $\begin{array}{r}120 \\
80 \\
1.5 \\
1 \\
9\end{array}$ & $\begin{array}{c}120 \\
80,75 \\
1.5,1.0 \\
1,3 \\
9\end{array}$ & $\begin{array}{c}120 \\
75 \\
1.0 \\
10 \\
6\end{array}$ & $\begin{array}{l}120 \\
75 \\
1.0 \\
10 \\
10\end{array}$ \\
\hline $\begin{array}{lr}\text { Pattern height } & (\mu \mathrm{m}) \\
\text { Sensitivity } & \left(\mathrm{mJ} / \mathrm{cm}^{2}\right)\end{array}$ & $\begin{array}{r}1.1 \\
7\end{array}$ & $\begin{array}{r}1.0 \\
20\end{array}$ & $\begin{array}{c}0.5,1.1 \\
7\end{array}$ & $\begin{array}{c}1.1 \\
7\end{array}$ & $\begin{array}{c}1.0 \\
7\end{array}$ \\
\hline
\end{tabular}

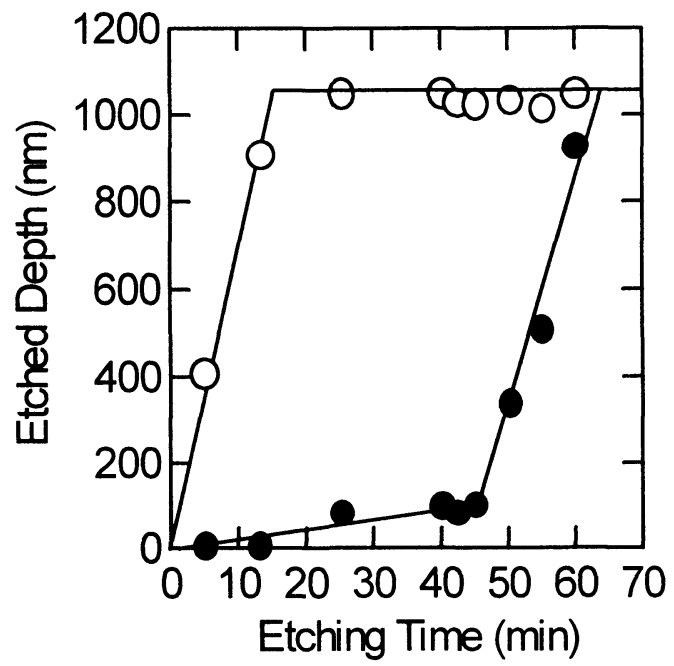

Fig. $2 \mathrm{O}_{2}$ RIE characteristics of SSS Resist layer \#50 before $(\bigcirc)$ and after $(O)$ silylation.

\subsection{Patterning of SSS Resists}

The SSS Resists were patterned under the conditions indicated in the lower half of Table 1. When Resists \#44 and \#46 were exposed to DUV light of $7 \mathrm{~mJ} / \mathrm{cm}^{2}$, steam-baked at $120{ }^{\circ} \mathrm{C}$ with hot water at $80^{\circ} \mathrm{C}$, and developed with $1.5 \mathrm{wt} \%$ aqueous TMAH for $1.0 \mathrm{sec}$, the exposed area of \#44 was not blanked, while that of \#46 was observed to be covered with traces of white powder. The reason was considered that the silylated sublayer was not removed completely by wet development in the former case, and that a part of the silylated sublayer turned into alkaline insoluble compound by reaction with excess steaming. The second specimen of Resist
\#46 was similarly patterned just replacing the hot water at $75^{\circ} \mathrm{C}$, and the bulk layer was blanked, but pattern height observed was 500-600 $\mathrm{nm}$. This result was ascribed to loss of the silylated sublayer during $\mathrm{O}_{2}$ RIE. In this way, strict control of sublayer thickness after wet development with concentrated solution is very difficult especially with a thin silylated sublayer. The third specimen of Resist \#46 was steam-baked with hot water at $75^{\circ} \mathrm{C}$, and developed with $1.0 \mathrm{wt} \%$ aqueous TMAH for 3.0 $\mathrm{sec}$, and a $1.1 \mu \mathrm{m}$ high pattern was formed with DUV sensitivity of $7 \mathrm{~mJ} / \mathrm{cm}^{2}$.

SSS Resists \#47 and \#50 were successfully patterned under the conditions cited in Table 1.

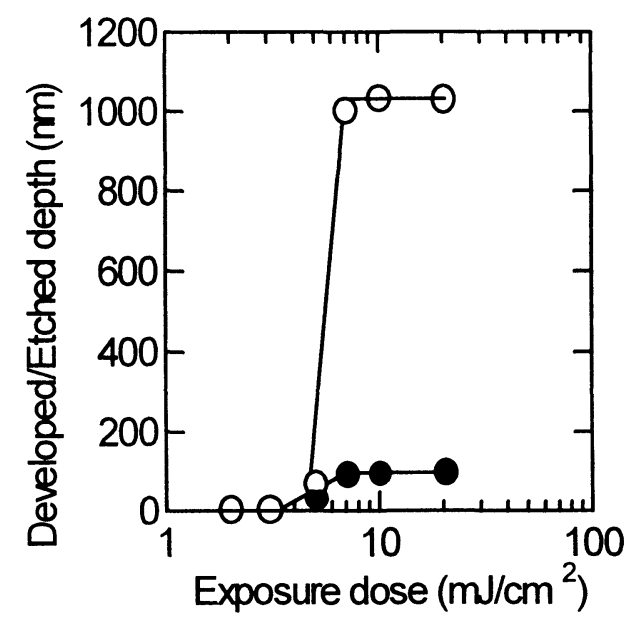

Fig. 3 DUV exposure characteristics of SSS Resist \#50 after wet development (O) and after $\mathrm{O}_{2} \operatorname{RIE}(\mathrm{O})$. 
Around $1 \mu \mathrm{m}$-thick resist layers were observed to be blanked in the area exposed to DUV light of 7 $\mathrm{mJ} / \mathrm{cm}^{2}$. The wet-developed depth and the depth amplified by $\mathrm{O}_{2}$ RIE with SSS Resist \#50 are plotted against the DUV dose in Fig. 3.

Another large specimen of SSS Resist \#50 was DUV exposed through a pattern mask for SEM, and treated similarly, though the conditions of wet development were with $1.5 \mathrm{wt} \% \mathrm{TMAH}$ for

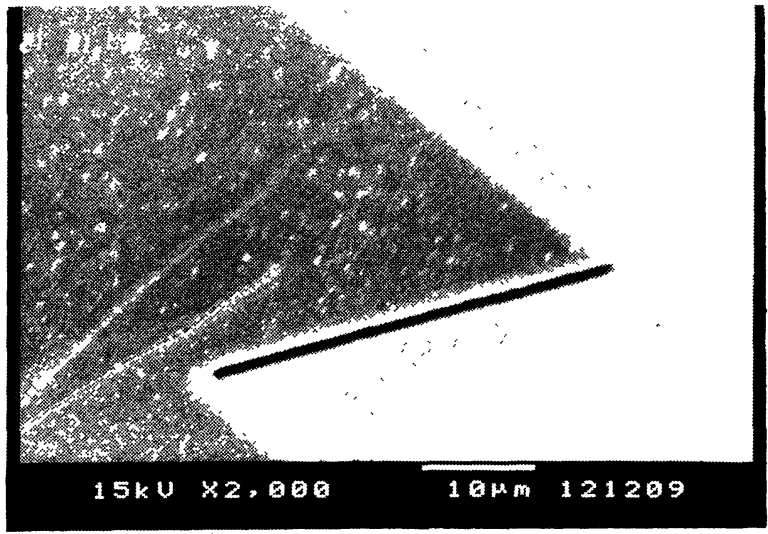

(a)
$5 \min$ or $6 \mathrm{~min}$. shown in Fig. 4.

The SEM pictures are In the exposed area of the pattern formed after wet-development for $5 \mathrm{~min}$, slight residue of white powder was observed, while in the case of that formed after prolonged development for $6 \mathrm{~min}$, the residue was not observed at all, and the border of exposed and unexposed areas was quite sharp.

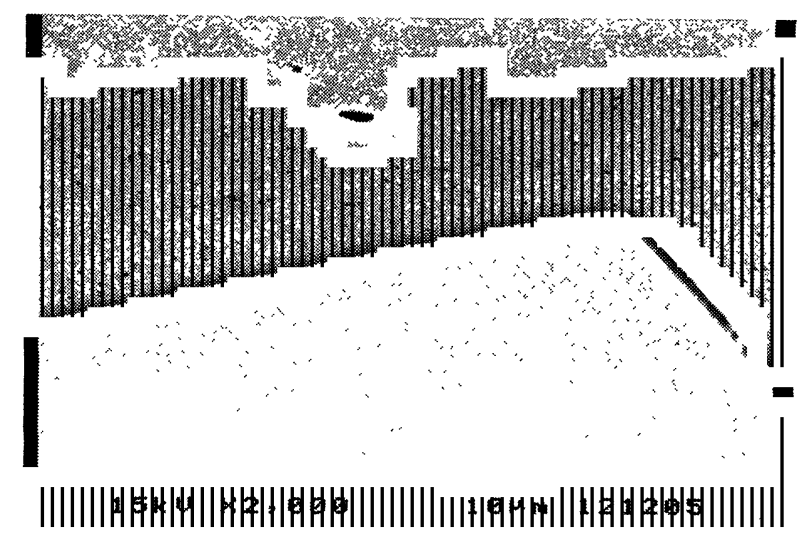

(b)

Fig. 4 SEM pictures of SSS Resist \#50 patterns after wet development with 1.5 wt $\%$ TMAH and $\mathrm{O}_{2}$ RIE: development (a) for $5 \mathrm{~min}$; (b) for $6 \mathrm{~min}$.

This SSS Resist process can be regarded as a hybrid of the bilayer resist and the surface imaging based on selective silylation or unsilylation in the exposed area. Therefore, it is expected to retain the merits of both processes, i.e., a simple single-layer process without using the Si-polymer prepared by many steps of complicated reaction, uniform and thin top imaging sublayer formation without spin-coating even on a wavy, not always flat, bottom layer, minimum pattern deterioration caused by low $\mathrm{Tg}$ of Si-polymers, no need for break-through etching after wet development under appropriate conditions. In particular, pre-exposure silylation eliminates the resolution deterioration caused by image expansion during silylation.

Further, acid-catalyzed hydrolysis of silylether during PEB is employed for solubilization of the exposed area of the silylated sublayer, and, namely, an enhanced sensitivity can be attained by the chemical amplification.

\section{Conclusion}

A SSS Resist with a thin silylated sublayer of $100 \mathrm{~nm}$ thickness, which has high transmittance to $157 \mathrm{~nm}$ and $13 \mathrm{~nm}$ radiation, formed a clear $1-\mu \mathrm{m}$ high pattern with a DUV sensitivity of 7 $\mathrm{mJ} / \mathrm{cm}^{2}$. It has attained the targeted performance necessary to extend the limit of DUV lithography toward the next generation.

\section{Acknowledgement}

The authors would thank Mr. Shoichiro Horie, President of Midori Kagaku Co. Ltd., for supplying onium salts and continuous encouragement.

\section{References}

1) K. Sugita, M. Ikagawa, K. Harada, M. Kushida and K.Saito, Jpn. J. Appl. Phys. 39 (2000) 669.

2) K. Sugita, M. Ikagawa, Liew C. M., M. Yamashita, K. Harada, M. Kushida and K. Saito, J. Photopolym. Sci. Technol. 13 (2000) 535.

3) K. Sugita, M. Ikagawa, Liew C. M., M. Yamashita, K. Harada, M. Kushida and K. Saito, in "Forefront of Lithographic Materials Research" (Proc. Intern'l Conf. Photopolym. (McAfee, NJ, Oct.2000)), H. Ito, M. M. Khojasteh and W. Li Eds., Soc. Plastic Eng., Hopewell Junction, NY (2001) p.203.

4) K. Sugita, M. Yamashita, Liew C. M., K. Harada, M. Kushida and K. Saito, Jpn. J. Appl. Phys. 40 (2001) 6658.

5) S. Kishimura, M. Sasago, M. Shirai and M. Tsunooka, Jpn. J. Appl. Phys. 38 (1999) 7104.

6) N. N. Matsuzawa, H. Oizumi, S. Mori, S. Irie, S. Shirayone, E. Yano, S. Okazaki, A. Ishitani and D. A. Dixon, Jpn. J. Appl. Phys., 38 (1999) 7109. 